\title{
Um estudo a respeito das evidências de aprendizado docente no PIBID da Licenciatura em Física+"
}

\author{
Marcus Vinícius Martinez Piratelo ${ }^{1}$ \\ Programa de Pós-Graduação em Ensino de Ciências e \\ Educação Matemática - Universidade Estadual de Londrina (UEL) \\ Marinez Meneghello Passos \\ Departamento de Matemática - UEL \\ Sergio de Mello Arruda ${ }^{1}$ \\ Departamento de Física - UEL \\ Londrina - PR
}

\section{Resumo}

Neste artigo apresentamos resultados de uma investigação que teve por objetivo analisar o processo de aprendizagem da docência no contexto do programa PIBID. Nesta situação estudada, buscamos por evidências de aprendizado docente em um grupo de estudantes da Licenciatura em Física, bolsistas do PIBID, por intermédio de um instrumento denominado Focos da Aprendizagem Docente (FAD). Como resultado das análises, além da conclusão de que o PIBID pode ser considerado uma configuração propícia para o aprendizado da docência, foi possível constatar que as atividades realizadas na escola possibilitaram que os estudantes: (i) enriquecessem o conhecimento de 'casos' relacionados ao contexto ensino-aprendizagem; (ii) ampliassem as reflexões sobre sua própria prática em sala de aula, antes e após a sua realização; $e$

\footnotetext{
${ }^{+}$Learning to teach in PIBID in Bachelor Degree in Physics

* Recebido: julho de 2013.

Aceito: abril de 2014.

Com o apoio da CAPES.
}

Caderno Brasileiro de Ensino de Física, v. 31, n. 3, p. 493-517, dez. 2014. 
(iii) diminuíssem sua dependência em relação ao professor supervisor, aumentando a sua autonomia docente.

Palavras-chave: Formação inicial de professores de Física. PIBID. Focos da aprendizagem docente.

\begin{abstract}
This article presents the results of an investigation which aimed to analyze the learning process of teaching in the PIBID project. In this study, we search for evidence of learning in teaching from a group of students in Physics Bachelor Degree, fellows of PIBID, through an instrument called the Strands of Teacher Learning (FAD). The analysis results, besides the conclusion that the PIBID can be considered as a good setting for the teaching learning we realize that the activities at school enabled the students to: (i) enrich the knowledge of 'cases' related to the teaching and learning context, (ii) broaden the reflections on their own practice in the classroom before and after its completion, and (iii) decreased their dependence on the teacher supervisor, increasing their teaching autonomy.
\end{abstract}

Keywords: Initial training of Physics teachers. PIBID. Strands of teacher learning.

\title{
I. Introdução
}

De acordo com Gómez (1997, p. 95), a escola nas sociedades industrializadas "conseguiu chegar aos lugares mais inacessíveis e às camadas sociais mais desfavorecidas". Entretanto, há insatisfação quanto aos resultados obtidos a partir "de longos e custosos processos de escolarização".

Considerando fatores como a organização social da escola e a elaboração de currículos, devemos ressaltar a responsabilidade do professor para que esse trabalho seja significativo, como nos indica o autor:

Desde há alguns anos, e cada dia com maior intensidade, as atenções estão viradas para o professor, enquanto profissional responsável pela natureza e qualidade do cotidiano educativo na sala de aula (GÓMEZ, 1997, p. 95). 
Gómez (1997, p. 96) complementa suas colocações indicando que "a formação destes profissionais é o eixo da atual controvérsia", pois, como afirma García (1997, p. 54), "a formação de professores não é um conceito unívoco".

Sendo a escola, para García (1997, p. 102), "um meio ecológico complexo", um "cenário psicossocial vivo e mutável, definido pela interação simultânea de múltiplos fatores e condições", os problemas provenientes desse meio são de natureza prática e necessitam de um tratamento singular.

As reflexões suscitadas pelo exercício da prática têm valor formativo de grau elevado para o futuro professor, tornando a sala de aula um local de investigação que, de forma alguma, pode reduzir-se a um espaço em que se aplicam técnicas apreendidas de maneira mecânica e sistematizada.

Para García (1997, p. 112):

O que se tenta formar através do currículo profissional é a capacidade de intervir de forma competente em situações diversas; ora, esta capacidade é um conjunto coerente, de caráter cognitivo e afetivo, explicativo e normativo, de conhecimentos, capacidades, teorias, crenças e atitudes (grifo nosso).

A realidade social não se encaixa perfeitamente em esquemas, e os fenômenos cuja origem está na prática são constituídos de dimensões como incerteza e instabilidade, não adaptáveis ou solucionáveis por meio de técnicas ou estratagemas. A tarefa do professor não pode consistir na escolha de procedimentos para solucionar problemas.

A área de formação de professores propõe-se a formar novos profissionais para a prática, a fim de que o docente seja autônomo e desenvolva capacidades que mesclem o cognitivo e o afetivo, o explicativo e o normativo.

Ainda, segundo García (1997, p. 112):

O pensamento prático do professor não pode ser ensinado, mas pode ser aprendido. Aprende-se fazendo na e sobre a ação. Através da prática é possivel apoiar e desenvolver o pensamento prático, graças a uma reflexão conjunta (e recíproca) entre o aluno-mestre e o professor ou o tutor (grifo nosso).

O autor também complementa afirmando que "uma vez que não é possível ensinar o pensamento prático, a figura do supervisor ou tutor universitário adquire uma importância vital" (GARCÍA, 1997, p. 113).

Partilhando da reflexão trazida por García (1997) de que: i) Há de se formar um profissional capaz de atuar frente às situações diversas e incertas; ii) $\mathrm{O}$ 
pensamento prático pode ser apreendido; iii) A figura do professor supervisor é de vital importância para o aluno, embasamos as escolhas realizadas para propor a pesquisa cujos resultados apresentamos neste artigo. Esses três pressupostos inspiraram os movimentos investigativos desenvolvidos por nós ao buscarmos evidências de aprendizado docente no Programa Institucional de Bolsa de Iniciação à Docência (PIBID).

Por conseguinte, algumas certezas e questionamentos se colocam: assumindo que é possível aprender a ser docente, perguntamos - que fatores contribuem com esse aprendizado?

Diante do exposto, optamos por estudar o aprendizado docente no PIBID, segundo um instrumento denominado Focos da Aprendizagem Docente (FAD), e que será apresentado com detalhes na próxima seção deste artigo.

Sendo assim, a questão anteriormente colocada passa a ser reformulada com as seguintes características: quais evidências de aprendizado docente podem ser encontradas em um grupo de estudantes, licenciandos de Física, bolsistas do programa PIBID, assumindo por categorias a priori os Focos da Aprendizagem Docente?

As discussões e análises aqui apresentadas constituem parte dos resultados de um programa de pesquisa, cujo objetivo geral é a aplicação dos focos de aprendizagem para investigar a aprendizagem científica e/ou aprendizagem docente em diferentes configurações, sejam elas formais, não formais ou informais (ARRUDA et al., 2012; FREGOLENTE, 2012; ARRUDA et al., 2013a; ARRUDA et al., 2013b; FEJOLO et al., 2013; MORYAMA et al., 2013; PIRATELO, 2013).

\section{Focos da aprendizagem docente}

Para Arruda et al. (2012) "há muito tempo se sabe que o avanço teórico de um campo pode ser alcançado por meio de analogias". Por intermédio delas, elaboraram um instrumento denominado Focos da Aprendizagem Docente (FAD), tendo por inspiração os Focos da Aprendizagem Científica, presentes no National Research Council (NRC, 2009), através de um relatório nominado Learning Science in Informal Environments: People, Places and Pursuits. Esse documento refere-se às distintas formas de aprendizagem científicas que podem ocorrer em configurações de aprendizado informal, como nos museus de ciência, por exemplo.

Nesse relatório, são apresentados os Strands of Science Learning (NRC, 2009 , p. 4-43), que "articulam um conjunto de seis habilidades científicas específicas associadas a ambientes de aprendizagem informal" (ARRUDA et al., 2012, p. 3). 
Por motivos relacionados à dificuldade de tradução, os Strands foram denominados focos e o termo Strands of Science Learning resultou em Focos da Aprendizagem Científica, que estão descritos a seguir:

Quadro 1 - Focos da Aprendizagem Científica.

Foco 1 [interesse científico]. O estudante experimenta interesse, envolvimento emocional, curiosidade e motivação para aprender sobre fenômenos do mundo natural e físico.

Foco 2 [conhecimento científico]. O estudante compreende e utiliza os principais conceitos, explicações, argumentos, modelos, teorias e fatos científicos criados para a compreensão do mundo natural.

Foco 3 [prática científica]. O estudante se envolve com a prática científica, manipulando, testando, observando, gerando e explicando as evidências científicas, redefinindo teorias e construindo novos modelos baseados na observação e dados experimentais.

Foco 4 [reflexão sobre a ciência]. O estudante reflete sobre a ciência como uma maneira de conhecer, sobre sua história, sobre os processos, conceitos e instituições científicas e sobre o seu próprio processo de aprendizado sobre os fenômenos.

Foco 5 [comunidade científica]. O estudante participa de atividades desenvolvidas em uma comunidade científica e aprende as práticas com outros, utilizando a linguagem e as ferramentas científicas, assimilando valores dessa comunidade.

Foco 6 [identidade científica]. O estudante pensa sobre si mesmo como um aprendiz da ciência e desenvolve uma identidade como alguém que conhece, utiliza e, às vezes, contribui para a ciência.

Fonte: Arruda et al. (2012, p. 4).

Os focos apresentados no Quadro 1 caracterizam-se como evidências de aprendizado científico que, mesmo sendo atribuídos a diferentes dimensões de aprendizado, trazem interligações entre si, de modo que "o progresso em um deles contribui para o desenvolvimento dos outros" (NRC, 2010, p. 2-5).

Tomando por ponto de partida o que temos no Quadro 1, um novo quadro foi elaborado. Para sua construção, foi necessário criar, para cada um dos focos 
referentes à aprendizagem científica, uma argumentação que sustentasse a analogia com a aprendizagem docente, dentro de uma perspectiva relacionada à formação de professores.

Conforme Sacristán $(2005$, p. 86), "os professores, por mais que pareça estranho, são pessoas que sentem e querem [...], não só pensam”. Em consequência disso, deveríamos dar mais importância "[...] aos motivos da ação do professorado, pois temos educado as mentes, mas não o desejo, não educamos a vontade". Dewey (1959) afirma que conhecer os métodos é suficiente apenas quando há desejo e vontade de empregá-los. Portanto, ao estudarmos o aprendizado da docência, é fundamental que seja levado em consideração o interesse do docente em relação à sua profissão.

Interessando-se pelo seu trabalho, o professor pode constituir um repertório de práticas que direcionarão suas atuações futuras. Constrói, portanto, saberes (TARDIF, 2012; GAUTHIER, 2006) oriundos de sua profissão. A esses saberes e reflexões construídos e proporcionados pela prática, Arruda et al. (2012) atribuíram como pertencentes ao segundo foco, referente ao conhecimento prático.

A partir da ligação íntima entre o saber dos professores e sua utilização nas situações práticas do exercício da profissão docente, os autores justificaram a junção dos focos relacionados ao conhecimento e à prática. Com essa união, elaboraram o foco referente ao conhecimento prático da docência, sem separar o conhecimento da prática, como está nos focos da aprendizagem científica.

Devido à importância dos conceitos apresentados por Schön $(1983,2000)$ para a descrição de uma nova epistemologia da prática, várias pesquisas e trabalhos direcionam-se à utilização do termo reflexão e às concepções por ele geradas para a elaboração de iniciativas que objetivam superar a racionalidade técnica.

Para Schön $(1983,2000)$, a reflexão é formativa (temos aqui o terceiro foco). Na sala de aula, o professor depara-se com as mais diversas situações e, através de um pensamento dirigido ao trabalho diário, é capaz de produzir conhecimento sobre sua prática. Analisa, portanto, os momentos de sua atuação e reflete sobre eles sem a urgência que demandam as atuações em sala de aula. Além disso, elabora estratégias de melhoria, examina os momentos ocorridos, reconsidera ações. A partir de um movimento introspectivo, o professor pode ser capaz de racionalizar, justificar e, consequentemente, expressar o porquê de suas ações.

\footnotetext{
2 Estamos utilizando a definição de saber de Tardif (2012, p. 199), que o caracteriza como "unicamente os pensamentos, as ideias, os juízos, os discursos, os argumentos que obedeçam a certas exigências de racionalidade".
} 
Entretanto, as práticas individualizadas podem favorecer o isolamento e reforçar "uma imagem dos professores como transmissores de um saber produzido no exterior da profissão" (NÓVOA, 1997, p. 26-27).

É necessário, pois, conceber o professor como um sujeito atuante em uma comunidade que construa, na e pela escola, conhecimentos objetivados em sua transformação, não se preocupando apenas com a própria formação. Os professores são aptos a refletir coletivamente com a finalidade de transformar a situação em que vivem, são capazes de aprender uns com os outros. Logo, o quarto foco referese ao aprendizado coletivo, ou seja, ao aprendizado em comunidade.

Segundo Nóvoa (1997), a partilha de experiências e saberes constitui espaços de formação mútua, onde cada professor desempenha os papéis de formador e aprendiz. A fim de aprender com o outro e com o ambiente social e humano, a formação deve abranger a configuração escolar.

Todavia, identificar-se com o trabalho docente é também uma maneira de aprender sobre a docência. Como coloca Codo (1992, p. 135), "a vida dos homens, sem dúvida, não se reduz ao trabalho, mas também não pode ser compreendida na sua ausência". Para Fischmann (1994, p. 62), "o corpo docente ganhará sua identidade - marca peculiar - no exercício competente de seu ofício". Nesse sentido, a identidade do professor caracteriza-se como mais um dos FAD.

Portanto, o Quadro 2, elaborado segundo certa analogia com os focos apresentados no Quadro 1, traz os Focos da Aprendizagem Docente, que serão utilizados por nós como categorias a priori para evidenciar se, no contexto investigado, os estudantes da Licenciatura em Física aprenderam a docência.

Quadro 2 - Focos da Aprendizagem Docente.

Foco 1 [interesse pela docência]. O estudante experimenta interesse, envolvimento emocional, curiosidade, motivação, mobilizando-se para exercer e aprender cada vez mais sobre a docência.

Foco 2 [conhecimento prático da docência]. A partir do conhecimento na ação e com base na reflexão na ação, o estudante desenvolve o conhecimento de casos, um repertório de experiências didáticas e pedagógicas que orientam a sua prática cotidiana in actu.

Foco 3 [reflexão sobre a docência]. Frente a novos problemas originados de sua prática, os quais não conseguiu resolver no momento em que ocorriam, o futuro professor, com base em instrumentos teóricos, analisa a situação sistematicamente, envolvendo-se com a pesquisa e reflexão a posteriori sobre sua 
prática e o seu conhecimento acumulado sobre ela, de modo a resolver os problemas inicialmente detectados. Trata-se de desenvolver a dimensão da pesquisa no futuro professor.

Foco 4 [comunidade docente]. O estudante participa de atividades desenvolvidas em uma comunidade docente, aprende as práticas e a linguagem da docência com outros professores ou futuros professores, assimilando valores dessa comunidade e desenvolvendo a reflexão coletiva.

Foco 5 [identidade docente]. O estudante pensa sobre si mesmo como um aprendiz da docência e desenvolve uma identidade como alguém que se tornará futuramente um professor de profissão.

Fonte: Arruda et al. (2012, p. 9)

Arruda et al. (2012, p. 10) destacam algumas das configurações em que pode ser discutida a aprendizagem docente; entre elas temos: na formação inicial, nos cursos de licenciatura; no estágio supervisionado; na formação em serviço, continuada; nos cursos de capacitação de professores; em programas especiais de formação de professores como o Programa Institucional de Bolsas de Iniciação à Docência (PIBID); em situações informais do dia a dia, na família, no trabalho; em ambientes de educação informal planejados, como os museus, centros de ciências, entre outros. Em função desses destaques selecionamos esta situação para investigação - o PIBID, bem como o referencial que a apresenta como configuração apropriada para a aprendizagem da docência.

\section{O contexto da pesquisa e os procedimentos metodológicos}

Nosso interesse dirigiu-se ao Programa Institucional de Bolsas de Iniciação à Docência (PIBID) da Coordenadoria de Aperfeiçoamento do Pessoal do Ensino Superior (CAPES), pois é um projeto que tem por objetivo a inserção dos estudantes das licenciaturas nas salas de aula das escolas da Educação Básica pública, sob a responsabilidade de um professor experiente e atuante nesse nível de ensino, denominado professor supervisor.

Na configuração atual do PIBID, podem participar do projeto instituições públicas de Ensino Superior, instituições comunitárias, confessionais e filantrópicas, privadas sem fins lucrativos, entre outras. São quatro as modalidades de bolsas de participação no projeto: 
Estudantes matriculados em cursos de licenciatura das instituições de Ensino Superior conveniadas;

Coordenador institucional: docente responsável pela coordenação do projeto no âmbito da Instituição de Ensino Superior (IES) e interlocutor da CAPES;

Coordenadores de área: docentes das IES responsáveis pela coordenação e desenvolvimento dos subprojetos, nas áreas de conhecimento que participam do programa. Em IES com elevado número de bolsistas, podem ser definidos coordenadores de área de gestão de processos educacionais, que atuam como coordenador adjunto, apoiando o coordenador institucional para garantir a qualidade do projeto e o bom atendimento aos bolsistas;

Supervisores: professores das escolas públicas onde acontece a prática docente, designados para acompanhar os bolsistas de iniciação à docência. (BRASIL, 2012, p. 7)

O PIBID busca incentivar atividades desenvolvidas nas escolas conveniadas, fazendo com que seus professores atuem como coformadores dos futuros docentes.

Os princípios pedagógicos sobre os quais se construíram o PIBID estão de acordo com os estudos de Nóvoa (2009). São eles:

1. Formação de professores referenciada no trabalho na escola e na vivência de casos concretos;

2. Formação de professores realizada com a combinação do conhecimento teórico e metodológico dos professores das instituições de ensino superior e o conhecimento prático e vivencial dos professores das escolas públicas;

3. Formação de professores atenta às múltiplas facetas do cotidiano da escola e à investigação e à pesquisa que levam à resolução de situações e à inovação na educação;

4. Formação de professores realizada com diálogo e trabalho coletivo, realçando a responsabilidade social da profissão (apud BRASIL, 2012, p. 6).

Embasado nesses princípios, o PIBID tem como objetivos:

I - Incentivar a formação de docentes em nível superior para a educação básica; 
II - Contribuir para a valorização do magistério;

III - Elevar a qualidade da formação inicial de professores nos cursos de licenciatura, promovendo a integração entre educação superior e educação básica;

IV - Inserir os licenciandos no cotidiano de escolas da rede pública de educação, proporcionando-lhes oportunidades de criação e participação em experiências metodológicas, tecnológicas e práticas docentes de caráter inovador e interdisciplinar que busquem a superação de problemas identificados no processo de ensino-aprendizagem;

$V$ - Incentivar escolas públicas de educação básica, mobilizando seus professores como coformadores dos futuros docentes e tornando-as protagonistas no processo de formação inicial para o magistério; e,

$V I$ - Contribuir para a articulação entre teoria e prática necessárias à formação dos docentes, elevando a qualidade das ações acadêmicas nos cursos de licenciatura (BRASIL, 2012, p. 6).

Para a realização desta pesquisa, acompanhamos um grupo do projeto PIBID de uma instituição pública de ensino superior do estado do Paraná, cujas atividades eram, em alguns momentos, realizadas na escola em que o grupo atuava e em outros momentos eram propostas pelo grupo e desenvolvidas na universidade.

$\mathrm{Na}$ escola, os estudantes iniciaram sua participação no projeto realizando observações das aulas do professor supervisor, durante aproximadamente um semestre. Quando deram início às práticas em sala, durante o período de horaatividade $^{3}$ do professor supervisor, os estudantes eram orientados por ele, que procurava comentar, debater e sugerir ideias para melhoria das aulas futuras. Além disso, semanalmente, o grupo reunia-se na universidade para planejar atividades, entre elas a participação em eventos; aulas de reforço para os alunos da escola; elaboração de experimentos de baixo custo; dentre outras. Ocorriam, também, reuniões mensais em que eram discutidas as atividades realizadas pelo grupo e a participação em aulas sobre Astronomia e Astrofísica, que eram organizadas e ministradas pelo coordenador de área.

O grupo analisado era composto, inicialmente, por cinco estudantes, com idades entre 18 e 24 anos, sendo que quatro deles cursavam o segundo ano da Li-

\footnotetext{
${ }^{3}$ A hora-atividade é o tempo reservado ao professor em atividade, para estudos, planejamento, avaliação e outras atividades de cunho pedagógico.
} 
cenciatura em Física. Quando iniciaram as aulas, apenas quatro continuaram; destes quatro, selecionamos para análise dos dados duas entrevistas gravadas em vídeo e, posteriormente, transcritas, de cada um dos três estudantes que cursavam o segundo ano da Licenciatura em Física, sendo que apenas um deles já havia ministrado aulas em um curso de informática para alunos do $4^{\circ}$ ano do ensino fundamental (E1). Com o objetivo de manter o anonimato dos depoentes utilizamos a seguinte codificação E1, E2 e E3, sendo que a letra E corresponde ao estudante , e a numeração à quantidade de sujeitos depoentes, para as informações que aqui trazemos.

As entrevistas realizadas possuíam um roteiro semiestruturado, que foi seguido de maneira não muito rígida, e, quando necessário, foram feitas outras perguntas de forma a conseguir novas informações e esclarecimentos a respeito dos comentários já apresentados pelos depoentes. Seguimos alguns critérios descritos por Szymansky (2004, p. 24-27), como o aquecimento, fase inicial em que o entrevistador busca um contato mais informal com o entrevistado. Além disso, os objetivos da pesquisa foram a base para a elaboração das questões.

A seguir descrevemos as questões das duas entrevistas ${ }^{5}$ aplicadas a esses participantes da investigação:

\section{ENTREVISTA 1}

1. De quais atividades você participou no projeto PIBID?

2. Como foi para você participar e desenvolver estas atividades?

3. Como foi dar aulas? Explique.

4. Como você avalia suas aulas?

5. O que você mudaria? O que você faria diferente?

6. Para você, o que é ser professor?

7. Para você, o que é ser professor de Física?

8. O que você aprendeu no PIBID sobre ser professor?

9. O que o professor precisa saber para dar uma boa aula?

\footnotetext{
${ }^{4}$ Para esta pesquisa, o termo estudante está relacionado aos licenciandos do curso de Física, bolsistas do PIBID, e aluno refere-se aos que cursam a Educação Básica.

${ }^{5}$ As entrevistas em sua completude podem ser acessadas em Piratelo (2013).
}

Caderno Brasileiro de Ensino de Física, v. 31, n. 3, p. 493-517, dez. 2014. 
10. Como está sendo a atuação do professor supervisor em sala de aula?

11. Como o professor supervisor age antes, durante e depois das aulas que você ministra?

12. Como foram as aulas de seus colegas do projeto PIBID?

13. Como o professor supervisor agiu antes, durante e depois das aulas de seus colegas de PIBID?

\section{ENTREVISTA $2^{6}$}

1. Houve algum momento em que você se percebeu como professor? Se sim, em qual?

2. O que você aprendeu com o professor supervisor?

3. Por que você quis cursar a Licenciatura em Física?

4. Você quer ser professor?

Não foram retomadas as perguntas 10,11 e 13 na segunda entrevista. Acreditamos que questionar diretamente os estudantes a respeito do aprendizado com relação ao professor supervisor seria mais pertinente à pesquisa, pois os estudantes já haviam descrito as atitudes e maneira de agir do professor, que não apresentou mudanças em suas práticas durante o processo de tomada de dados.

As entrevistas foram transcritas, e, logo após, os trechos dos depoimentos foram categorizados, admitindo os focos da aprendizagem docente como categorias a priori para a análise dos dados, segundo a Análise Textual Discursiva (ATD) (MORAES; GALLIAZZI, 2011), descrita a seguir.

Optamos pelos procedimentos da ATD pelo fato de auxiliar na organização das informações, permitindo uma acomodação que possibilite evidenciar os relatos relacionados aos Focos da Aprendizagem Docente, o que a nosso ver não seria possível se adotássemos uma forma de leitura convencional.

A ATD segundo os autores é

${ }^{6}$ Foram reproduzidas as perguntas da Entrevista 1 com o intuito de comparar as respostas ao final da pesquisa. Foram acrescentadas as perguntas não descritas na relação anterior visando, principalmente, verificar se houve identificação com a docência durante a participação dos estudantes nas atividades do projeto PIBID. 
[...] um processo emergente de compreensão, que se inicia com um movimento de desconstrução, em que os textos do "corpus" "são fragmentados e desorganizados, seguindo-se de um processo intuitivo auto-organizado de reconstrução, com emergência de novas compreensões que, então, necessitam ser comunicadas e validadas cada vez com maior clareza em forma de produções escritas (MORAES; GALIAZZI, 2011, p. 41).

Com base nos procedimentos apresentados por essa metodologia, procuramos inicialmente ler as informações coletadas por meio das entrevistas, desconstruindo, ou seja, fragmentando os depoimentos segundo os focos que procurávamos. Isso nos levou ao processo de unitarização de trechos da entrevista com certa semelhança, considerando que os FAD foram assumidos como categorias a priori desde o início do processo interpretativo.

De acordo com Moraes e Galiazzi (2011, p. 18),

A desconstrução e a unitarização do "corpus" consiste num processo de desmontagem ou desintegração dos textos, destacando seus elementos constituintes. Significa colocar o foco nos detalhes e nas partes componentes dos textos, um processo de decomposição que toda análise requer.

Diferentes formas de se proceder com a pesquisa são concebidas com a unitarização:

Quando se conhecem de antemão os grandes temas da análise, as categorias a priori, basta separar as unidades de acordo com esses temas ou categorias. Uma pesquisa, entretanto, também pode pretender construir as categorias, a partir da análise. Nesse caso as unidades de análise são elaboradas com base nos conhecimentos tácitos do pesquisador, sempre em consonância com os objetivos da pesquisa (MORAES; GALIAZZI, 2011, p. 19).

Os autores completam:

[...] a unitarização é parte do esforço de construir significados a partir de um conjunto de textos, entendendo que sempre há mais sentidos do que uma leitura possibilita elaborar (MORAES; GALIAZZI, 2011, p. 49).

\footnotetext{
7 "O conjunto de documentos que será submetido aos procedimentos de análise" (BARDIN, 2011, p. 90).
} 
A busca por novas teorias, ainda que sob a sustentação de referenciais teóricos já consagrados, traz um caráter inovador à pesquisa que se constrói com os pressupostos da ATD.

A categorização é "um processo de comparação constante entre as unidades definidas no momento inicial da análise, levando a agrupamentos de elementos semelhantes" (MORAES; GALIAZZI, 2011, p. 23). A partir desse agrupamento, são elaboradas as categorias que sintetizam o fenômeno estudado e possibilitam a produção e a organização do metatexto, expressando "os sentidos lidos em um conjunto de textos constituídos de descrição e interpretação, representando o conjunto, um modo de teorização sobre os fenômenos estudados" (MORAES; GALIAZZI, 2011, p. 32). É, portanto, por meio das categorias, que são produzidas descrições e interpretações, e através do metatexto que as novas compreensões apreendidas podem ser comunicadas.

Foi, portanto, dessa forma que procedemos com relação à pesquisa desenvolvida. Após a leitura, desconstrução e unitarização dos dados, as falas dos estudantes foram categorizadas segundo os FAD, que proporcionaram interpretações que nos levaram às conclusões apresentadas neste artigo.

\section{Apresentação e análise dos dados}

Nesta seção, buscamos evidenciar, através de alguns ${ }^{8}$ depoimentos, o aprendizado da docência identificado nos depoimentos dos estudantes entrevistados, lembrando que os FAD são constituídos pelos seguintes focos: Foco 1 - Interesse; Foco 2 - Conhecimento prático; Foco 3 - Reflexão; Foco 4 - Comunidade; Foco 5 - Identidade.

\section{Foco 1 - Interesse}

Esta categoria está relacionada aos relatos dos estudantes em que o interesse, a motivação e o estímulo foram destacados como importantes para que procurassem aprender sobre a docência. Os estudantes declaram seu interesse pelas aulas que ministraram na escola, comentando a respeito do aprendizado decorrente da participação nas atividades que realizaram no projeto. Quando questionado sobre como foi dar aulas, o estudante E1 responde:

\footnotetext{
${ }^{8}$ Os fragmentos que apresentamos neste artigo são exemplos dos diversos relatos que compõem as entrevistas. Contudo, esclarecemos que as análises e as conclusões foram pautadas na coleta em sua completude.
} 
Eu gosto. Eu acho que está sendo fantástico, está sendo muito legal. Até agora eu não encontrei nenhuma dificuldade, então o que está acontecendo. Eu até agora estou superando minhas expectativas, até um ponto em que eu vou encontrar dificuldades e vou aprender com elas. [Entrevista 1]

Foi possível evidenciar também algumas justificativas a respeito do interesse pela docência. Para a estudante E2, a interação com os alunos era o que a motivava a ser professora:

Eu achei muito legal, porque eu perguntava as coisas e não sei se é porque eles estavam fazendo gracinha, mas participavam comigo. Eles conversavam comigo. Eu perguntava as coisas e eles respondiam. Eles não respondiam ou respondiam baixinho, eles falavam alto: "Não, é isso mesmo", ai eu olhava e falava: "Não, tá errado", $e$ eles iam "chutando". [Entrevista 1]

A estudante E3 compara a sala de aula com o que vivenciou em outras situações de emprego, como pode ser observado nos seguintes fragmentos de seus relatos: "Concluí que trabalhar como professora não é a mesma coisa do que você trabalhar em uma empresa [...] eu tenho visto que é divertido dar aulas" [Entrevista $1]$.

Os estudantes não apenas manifestavam seu interesse nas entrevistas, mas justificavam as razões pelas quais se interessavam e buscavam aprender sobre a docência. Para cada um deles, entretanto, os motivos foram diferentes. Para E1, estar superando as expectativas foi um dos motivos por seu interesse, para E2 foi a interação com os alunos, e para E3 foi a conclusão de que trabalhar como professora é "divertido". Convém comentar que os mesmos motivos apresentados acima, para cada um dos estudantes, repetiram-se para o caso da entrevista 2.

\section{Foco 2 - Conhecimento prático}

Temos neste momento a ênfase às experiências vivenciadas. A partir das reflexões realizadas durante a situação de ensino, o estudante elabora um conhecimento de maneira a nortear suas práticas futuras em sala de aula. De fato, esses licenciandos em Física envolveram-se nas práticas proporcionadas pela participação no projeto, o que possibilitou a inserção deles no contexto da sala de aula. Dessa forma, ficou evidente em alguns depoimentos o aprendizado com relação a este foco. Destacamos ainda que um dos temas mais abordados pelos estudantes foi o conteúdo e a gestão da sala de aula. E1, por exemplo, expõe que "[...] você 
tem que dominar primeiro seu conteúdo, depois você tem que aprender a dançar conforme a música. Às vezes você não precisa dominar a turma, você precisa saber andar com ela" [Entrevista 1]. E complementa:

Eu aprendi que o professor tem que desenvolver vários métodos para dar uma boa aula. [...] Por exemplo, são trinta alunos e um professor, então é mais fácil o professor dançar igual aos alunos do que os alunos dançarem igual ao professor. [Entrevista 1]

Para E2, aprender sobre a docência é aprender "a conviver com os alunos". Comenta, também, que o conteúdo necessita ser abordado de forma simples e dentro de um contexto: "[...] eu aprendi, estou aprendendo ainda, na verdade, a preparar aula. Na minha cabeça tudo o que eu colocasse no papel eu ia poder passar para os alunos, mas isso não é verdade. [...] então a gente tem que resumir" [Entrevista 1]. E3 relata que é necessário "também transformar aquilo que eu estudei numa linguagem acessível aos alunos, eu acho" [Entrevista 1].

Além disso, declara ter aprendido que:

Você tem que ir preparado. Porque se você vai lá só meia boca, vai lá de improviso, de conteúdo improvisado com atividade improvisada que você vai passar pra eles é bobagem, vai passar vergonha. Então é isso que eu aprendi. Aprendi que precisa ir preparado. Se não for pra se preparar então nem vai, nem vai porque senão não vai dar certo. [Entrevista 1]

Concluímos, a partir dos depoimentos apresentados, que conhecer sobre a docência na prática é gerir o conteúdo e a sala de aula, aprender a conviver com os alunos, expor o conteúdo de forma simplificada e preparar-se para as situações que o contexto escolar proporciona. É, portanto, aprender sobre a docência na prática, através do exercício de atividades didáticas e pedagógicas na sala de aula, na escola.

\section{Foco 3 - Reflexão}

Nesta categoria buscamos explicitar as reflexões sobre a docência, realizadas pelos estudantes, após sua ação em sala de aula. Ficou evidente em diversos depoimentos que o projeto PIBID foi capaz de suscitar reflexões a respeito da docência. Uma das formas mais frequentes de reflexão encontradas nas entrevistas foi no sentido de aperfeiçoamento da própria prática, identificação de problemas e propostas de solução. E1 expõe o que faria diferente para uma ação futura: 
Eu vou chegar e perguntar: "Gente, vocês lembram o que eu dei na aula passada? Vocês não lembram, então vamos pegar o caderno todo mundo". Então é uma coisa que tem, é uma coisa que eu já mudei da outra aula. Então isso é o que a gente vai aprendendo. Foi uma coisa que eu não fiz na primeira aula. [Entrevista 1]

Avaliar-se, também, foi uma das maneiras pelas quais os estudantes refletiram sobre a docência. Atribuíram adjetivações às suas atuações, relacionando-as às percepções diante do que havia acontecido na sala de aula. E1 comenta:

Igual, essas entrevistas, a gente está avaliando tudo, a gente está avaliando o começo do bimestre até eu aplicar essa última prova. Então, como eu faço? Eu faço uma avaliação, eu não faço só uma avaliação dos alunos, eu faço uma avaliação minha enquanto professor. [Entrevista 2]

Algumas reflexões realizadas consideram as contribuições para o aperfeiçoamento da própria prática. $\mathrm{Na}$ fala a seguir, a partir de uma análise realizada sem a urgência requerida no ato de ensino. É o que nos descreve E3:

Tem que parar e pensar muito bem porque a gente não, se avaliar dessa forma, a gente não faz isso constantemente, então a hora que a gente começa a se avaliar ali: "Nossa! O que será que eu aprendi até agora? Quanto que eu evolui até agora?" É dificil, você tem que parar, sentar e começar a pensar mesmo. Ajuda porque você consegue traçar, tipo, o que eu melhorei e o que eu preciso melhorar mais ainda, então essa é uma prática que tem que ser feita. [Entrevista 1]

Os estudantes refletiram a respeito da docência elaborando estratégias de aperfeiçoamento da própria prática e avaliando suas aulas passadas. Sem o caráter urgente requerido na prática docente, puderam avaliar e analisar suas atuações identificando soluções para os problemas enfrentados durante suas aulas, fato que pudemos evidenciar nas duas entrevistas.

\section{Foco 4 - Comunidade}

Para o caso deste grupo analisado, várias falas puderam ser consideradas como evidências de aprendizagem relativas a este foco. Fica explícito que a participação no projeto proporcionou o envolvimento dos estudantes com questões relativas ao contexto universitário e à escola pública, portanto, o aprendizado relacionado ao convívio com os professores de ambas as instituições pôde ser, tam- 
bém, observado. Outro destaque com relação à inserção e participação em uma comunidade pode ser observado, quando se reportam aos colegas bolsistas com quem atuam conjuntamente. E1 comenta: "Eu quando assisto à aula do outro, não é que eu estou lá pra botar defeito, estou indo lá pra apontar defeitos, estou indo lá pra ver o defeito e pra não cometer o mesmo erro. Esse é o intuito".

$\mathrm{O}$ aprendizado relacionado à participação em uma comunidade aparece, nos depoimentos, principalmente, articulado com o professor supervisor, aquela pessoa presente e atuante, e que se encontra em contato direto e constante com esses estudantes. E3 descreve o professor supervisor e suas atuações da seguinte forma:

Eu não sei por que o professor supervisor é um professor tão legal, sabe? Ele é divertido em sala de aula. Ele tem jogo de cintura com os alunos, sabe? Eu lembro quando assistia às aulas dele, que ele conseguia prender um pouco da atenção dos alunos. Ele começava a falar da matéria, daqui a pouco ele viajava, começava a falar de futebol, começava a falar da crise econômica de não sei onde. Depois ele conseguia voltar pra Física. Então eu admiro isso, sabe? [Entrevista 2]

Em função da admiração construída com relação a este professor supervisor, os estudantes puderam aprender, primeiramente, em situações de observação, todavia, ocorreram momentos em que um diálogo foi estabelecido e o aprendizado mostrou-se presente.

O professor já comentou uns erros comigo. Ele apontou uns erros que eu tive, e eu achei legal, e eu posso melhorar, tirar uns erros que ele falou. Que eu fiquei de costas. Falar para o quadro não é legal. Eu não tinha percebido, mas ele comentou, deve ser verdade. E acho que é isso mesmo. (E2) [Entrevista 1]

Conforme mencionado anteriormente, o aprendizado ocorreu também durante a convivência com professores da universidade.

A gente aprende a escrever, aprende coisinhas de Física mesmo que a gente deveria saber, matéria do ensino médio mesmo, mas no caso, preparar as aulas, ministrar as aulas. Como meu professor fala: Se a gente, quando a gente está nos três primeiros anos, o professor está aprendendo a matéria [...]. Ele fala que nos primeiros três anos 
o professor está aprendendo a matéria. Isso o professor que terminou a graduação. (E2) [Entrevista 1]

\section{Foco 5 - Identidade}

Houve poucos indícios de falas relacionadas à construção de uma identidade docente. A estudante E3 foi quem mais apresentou indícios, pois foi, no final do processo, aquela que explicitou com maior ênfase a decisão em ser professor.

Quando eu voltei lá no colégio, meus professores estão lá ainda, os professores que deram aula pra mim estão me vendo agora como uma professora. Então pensa na forma como eles não estão se sentindo. Valeu a pena, né? Digamos assim. Então eu acho que é gostoso. Você não tem pressão psicológica em cima de você. Tem dos alunos né? Mas não é a mesma coisa que você ter um patrão na tua, no teu pé ali e falando: produz, produz, produz. [Entrevista 2]

Mesmo sem explicitações a respeito do futuro e de manifestações sobre a idealização de vir a ser professor, os demais estudantes que fizeram parte desta pesquisa trazem indícios em seus depoimentos de momentos de identificação com a docência, como pode ser observado nesses dois exemplos que apresentamos a seguir: "[...] eu me achei uma excelente professora, porque eu consegui explicar" (E2) [Entrevista 1]; "[...] eu acho que eu me percebi como professor no momento em que eu fui lá pra dar aula, eu sou professor da turma. Igual, tem aluno que me chama pelo nome e tem aluno que me chama de professor" (E1) [Entrevista 2].

Como pôde ser observado no que apresentamos neste artigo até o momento, os bolsistas que fizeram parte desta investigação deixam evidente em seus relatos que aprenderam sobre a docência participando deste projeto do PIBID. Contudo, podemos avançar um pouco mais nesta busca, procurando destacar os Focos da Aprendizagem Docente com maior frequência nos depoimentos e que, por conseguinte, podem nos levar aos fatores que influenciaram este aprendizado.

\section{Um outro olhar sobre os dados}

Comparando as duas entrevistas dos três estudantes, na íntegra, e os focos que pudemos nelas identificar, foi possível construir dois gráficos de setores que mostram o movimento dos depoimentos. Para uma maior compreensão dos gráficos apresentados a seguir, construímos o Quadro 3, onde representamos cada um dos focos por uma codificação referente ao aprendizado da docência que representam. 
Quadro 3 - Focos da Aprendizagem Docente e Codificação.

\begin{tabular}{|l|l|}
\hline Foco & Codificação \\
\hline Foco 1 - Interesse pela docência & (INT) \\
\hline Foco 2 - Conhecimento prático da docência & (CHN) \\
\hline Foco 3 - Reflexão sobre a docência & (REF) \\
\hline Foco 4 - Comunidade docente & $(\mathrm{COM})$ \\
\hline Foco 5 - Identidade docente & (IDT) \\
\hline
\end{tabular}

Com relação ao Foco 1 (interesse) - nas Entrevistas 1 e 2 a incidência de depoimentos foi semelhante (12\% e $13 \%$, respectivamente) - e ao Foco 5 (identidade) - na Entrevista 1 a incidência foi de 3\% e na Entrevista 2 a incidência foi de $4 \%$ - percebe-se que as variações entre o momento inicial da participação no projeto e a final não tiveram uma relevante alteração quanto à frequência com que falam sobre a temática de cada foco.

Porém, com relação aos demais focos, ficam perceptíveis as mudanças. No foco 2 - temos inicialmente $25 \%$ de incidência, que passa a ser de $32 \%$ na segunda entrevista. Ao retomarmos os depoimentos alocados nesse foco, é possível verificar que o envolvimento com a prática e com as experiências vivenciadas em sala de aula - desses três estudantes analisados - proporcionaram aprendizados aos estudantes, o que, por conseguinte, refletiu no aumento da quantidade de relatos relacionados a ele. Resultados que antecedem esta pesquisa e que contribuem com essa estruturação e busca por avanços no campo investigativo podem ser observados em outras pesquisas que utilizaram os FAC - Focos da Aprendizagem Científica em Fejolo et al. (2013); os FAD - Focos da Aprendizagem Docente em Fregolente (2012), em Arruda et al. (2012) e em Moryama et al. (2013); os FAP - Focos da Aprendizagem para a Pesquisa em Teixeira (2013).

A observação do Foco 3 - que se altera de uma incidência de declarações de 35\% para 39\% na Entrevista 2 - também nos remete à revisão do que foi dito. Percebe-se a intensificação das reflexões durante a atuação e, em momentos posteriores, sobre a ação já realizada em sala de aula, principalmente, na busca por soluções e possibilidades para supostos erros ou defeitos por eles detectados ou apontados pelo professor supervisor. Temos aí a evidência da construção de um repertório de atitudes e de análise de situações de sala de aula, que passa a se configurar como 'histórias já vividas' e que contribuirão com decisões e encaminhamentos futuros. 


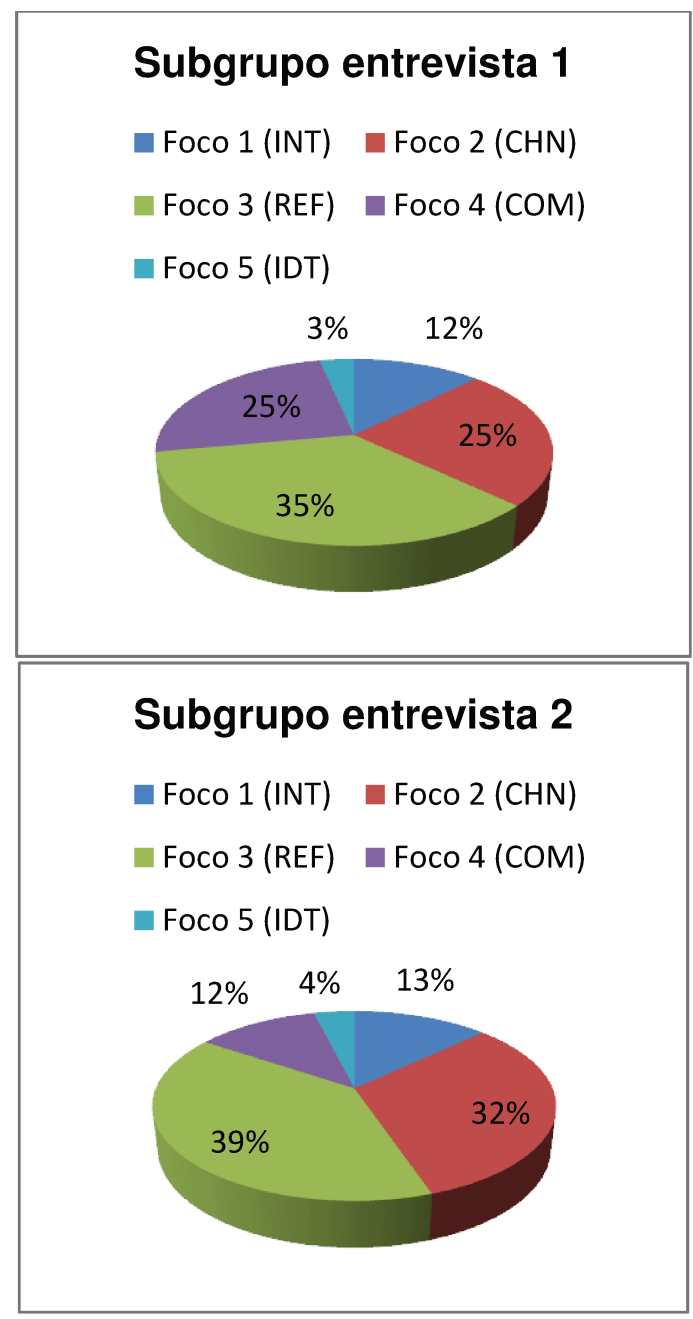

Fonte: Os autores.

Gráficos 1 e 2 - Comparação da frequência dos FAD nas entrevistas.

O Foco 4 - como é possível perceber - sofreu uma redução de $25 \%$ para $12 \%$, e foi o que mais se alterou nesses depoimentos que compõem o nosso corpus analítico. Quando retomamos todos os relatos alocados neste foco em uma leitura contínua, é possível inferir que a preocupação inicial por não pertencer a uma comunidade escolar ou professoral foi atenuando, ou seja, ao ver-se atuando e imerso nesse contexto, e se sentindo cada vez mais professor, o pertencimento a esta co- 
munidade deixou de ser um problema; por isso, acreditamos que a incidência de relatos a respeito do foco tenha diminuído.

\section{Considerações finais}

É certo que há configurações, como o programa PIBID, que propiciam que se aprenda sobre a docência, isso foi o que ocorreu com os licenciandos em Física pesquisados. O PIBID, no entanto, parece ter se revelado um programa propício para que esse aprendizado ocorresse.

Temos consciência de que em um artigo não há quantidade de páginas suficiente para trazermos todos os dados de uma pesquisa que foi desenvolvida durante dois anos. Todavia, o que apresentamos e ao observarmos os dados em sua completude (e que podem ser acessados em Piratelo (2013)), podemos concluir que por intermédio do instrumento denominado Focos da Aprendizagem Docente (FAD) percebem-se quais evidências de aprendizagem docente se destacaram nesta situação analisada.

Ao interpretarmos os depoimentos dos bolsistas do PIBID encontramos os cinco Focos da Aprendizagem Docente, o que nos permitiu concluir que eles aprenderam a respeito da docência, interessando-se por ela; conhecendo e se apropriando de um repertório de possibilidades para a realização de intervenções práticas em sala de aula; refletindo a respeito das situações de gestão do conteúdo e gestão da classe; engajando-se em uma comunidade escolar e professoral; e, por fim, identificando-se com o exercício da docência.

Contudo, nem todos os focos foram destacados com a mesma ênfase pelos depoentes, e, em função desta constatação durante o processo de organização do corpus de pesquisa, procuramos meios de comparar a incidência dos relatos durante as entrevistas, averiguando o que mais eles enfatizaram a respeito desse aprendizado sobre a docência. Desse movimento foi possível constatar que: as experiências proporcionadas pela participação neste projeto enriqueceram o conhecimento de 'casos' relacionados ao contexto ensino-aprendizagem, ampliando também o processo reflexivo durante e após a prática e diminuindo a dependência dos bolsistas com relação ao professor supervisor, aumentando a autonomia de cada acadêmico. 


\section{Referências}

ARRUDA, S. M.; PASSOS, M. M.; FREGOLENTE, A. Focos da aprendizagem docente. Alexandria - Revista de Educação em Ciência e Tecnologia, v. 5, n. 3, p. $25-48,2012$.

ARRUDA, S. M.; PASSOS, M. M.; PIZA, C. A. M.; FELIX, R. A. B. O aprendizado científico no cotidiano. Ciência \& Educação, Bauru, v. 19, n. 2, p. 481-498, 2013a.

ARRUDA, S. M.; FREGOLENTE, A.; PASSOS, M. M. Aprendizagem científica no espetáculo teatral: a Ciência em Peças. Capítulo de livro no prelo. $2013 \mathrm{~b}$.

BARDIN, L. Análise de conteúdo. Lisboa: Edições 70, 1977, 3. ed., 2011.

BRASIL. Relatório de Gestão 2009-2011 da Diretoria de Formação de Professores da Educação Básica. Brasília, DF, 31 jul. 2012. Disponível em: $<$ http://www.capes.gov.br/images/stories/download/bolsas/DEB_Pibid_Relatorio2009_2011.pdf>. Acesso em: 28 jan. 2013.

CODO, W. Indivíduo: trabalho e sofrimento. Petrópolis: Vozes, 1992.

DEWEY, J. Como pensamos. 3. ed. São Paulo: Editora Nacional, 1959.

FEJOLO, T. B.; ARRUDA, S. M.; PASSOS, M. M. A aprendizagem científica informal no PIBID: identificando e interpretando os focos. Caderno Brasileiro de Ensino de Física, v. 30, n. 3, p. 628-649, dez. 2013.

FISCHMANN, R. Redefinição do público e do privado: contribuição para a reflexão educacional. In: ALVES, M. L. (Org.). Escola: espaço de construção da cidadania. São Paulo: F. D. E., 1994.

FREGOlente, A. The Theatrical Show, Science in Pieces and Student Teachers Scientific Learning Opportunities and Views on Their Teacher Training. 2012. 47f. Dissertação (Mestrado em Ensino de Ciências e Educação Matemática) - Universidade Estadual de Londrina, Londrina.

GARCÍA, C. M. A formação de professores: novas perspectivas baseadas na investigação sobre o pensamento do professor. In: NÓVOA, A. (Coord.). Os professores e a sua formação. 2. ed. Lisboa: Dom Quixote, 1997. p. 51-77. 
GAUTHIER, C. et al. Por uma teoria da pedagogia: pesquisas contemporâneas sobre o saber docente. Ijuí: Unijuí, 2006.

GÓMEZ, A. P. O pensamento prático do professor: a formação do professor como profissional reflexivo. In: NÓVOA, A. (Coord.). Os professores e a sua formação. 2. ed. Lisboa: Dom Quixote, 1997. p. 93-114.

MORAES, R.; GALIAZZI, M. C. Análise textual discursiva. Ijuí: Unijuí, 2011.

MORYAMA, N.; PASSOS, M. M.; ARRUDA, S. M. Aprendizagem da docência no PIBID-Biologia. Alexandria - Revista de Educação em Ciência e Tecnologia. Aceito para publicação. 2013.

NATIONAL RESEARCH COUNCIL. Learning science in informal environments: people, places, and pursuits. Committee on learning science in informal environments, national research council of the national academies. Washington, DC: The National Academies Press, 2009. Disponível em: <http://www.nap.edu/catalog/12190.html>. Acesso em: 22 dez. 2012.

NATIONAL RESEARCH COUNCIL 2010. FENICHEL, M.; SCHWEINGRUBER, H. A. Surrounded by Science: Learning Science in Informal Environments. Board on Science Education, Center for Education, Division of Behavioral and Social Sciences and Education. Washington, DC, 2010. The National Academies Press, Washington, DC, 2010. Disponível em: $<$ http://www.nap.edu/catalog.php?record_id=12614>. Acesso em: 2 dez. 2012.

NÓVOA, A. Os professores e a sua formação. 2. ed. Lisboa: Dom Quixote, 1997.

Para uma formação de professores construída dentro da profissão. Revista Educación. Madrid, 2009.

PIRATELO, M. V. M. Um estudo sobre o aprendizado docente no projeto PIBID/UEL - licenciatura em Física. 2013. 142f. Dissertação (Mestrado em Ensino de Ciências e Educação Matemática) - Universidade Estadual de Londrina, Londrina.

SACRISTÁN, J. G. Tendências investigativas na formação de professores. In: PIMENTA, S. G.; GHEDIN, E. (Coord.). Professor reflexivo no Brasil: gênese e crítica de um conceito. São Paulo: Cortez, 2005. 
SCHÖN, D. Educando o profissional reflexivo: um novo design para o ensino e a aprendizagem. Porto Alegre: Artes Médicas Sul, 2000.

The reflective practioner. New York: Basic Books, 1983.

TARDIF, M. Saberes docentes e formação profissional. 13. ed. Petrópolis: Vozes, 2012.

TEIXEIRA, L. A. Tornando-se pesquisadores: Um estudo a partir da análise de Memórias de um grupo de pesquisa em Educação em Ciências e Matemática. 2013. 179f. Dissertação (Mestrado em Ensino de Ciências e Educação Matemática) - Universidade Estadual de Londrina, Londrina. 